\title{
"Como cosa nuestra y no como cosa extraña": la hagiografía jesuita de una beata otomí y la autonomía económica de las parcialidades indígenas de México bajo las Reformas Borbónicas
}

\author{
"As a matter concerning us and no other": \\ The Jesuit Hagiography of an Otomí Lay Sister and the \\ Economic Autonomy of Mexico's Indigenous Communities \\ Under the Bourbon Reforms
}

\author{
BRYAN DAVID GREEN ${ }^{a}$ \\ ${ }^{a}$ Pontificia Universidad Católica de Valparaíso. \\ Correo electrónico: bryan.green@pucv.cl
}

Este artículo examina la Carta edificante sobre la vida de Salvadora de los Santos Ramírez (17011762), escrita por el jesuita novohispano Antonio de Paredes (1691-1767), dentro del contexto de su primera aparición en 1762 y su reedición tras la expulsión de la Compañía de Jesús. Mientras estudios recientes de la obra se han enfocado en las polémicas sobre el ingreso de mujeres indígenas a los conventos novohispanos, o con la promoción de modelos de santidad entre los sectores populares del virreinato, el presente trabajo aborda el contexto de su reedición por encargo de los gobernadores indígenas de San Juan Tenochtitlan y Santiago Tlatelolco en 1784 y 1791. A través de una investigación de archivo sobre los firmantes de la dedicatoria que precede las reediciones de la Carta edificante, se descubren vínculos directos entre esta y los esfuerzos por conservar la relativa autonomía espiritual y económica de las comunidades indígenas novohispanas frente a las Reformas Borbónicas. El análisis demuestra un sofisticado manejo de la cultura jurídico-notarial y de la imprenta de parte de las élites indígenas de México, quienes aprovecharon el discurso hagiográfico para esgrimir una crítica mordaz contra los abusos que sufrían sus comunidades a manos de oficiales locales y metropolitanos.

Palabras claves: Nueva España, Reformas Borbónicas, jesuitas, indígenas, hagiografía.

This article examines the edifying letter on the life of Salvadora de los Santos Ramírez (1701-1762), written by the novo-Hispanic Jesuit Antonio de Paredes (1691-1767), within the context of its first appearance in 1762 and its republication after the expulsion of the Society of Jesus. While recent studies of the work have focused on the controversies regarding the religious vocation of indigenous women, or with the promotion of models of piety among the diverse sectors of the viceroyalty, 
the present work addresses the context of the work's republication in 1784 and 1791, which was financed by the indigenous governors of San Juan Tenochtitlan and Santiago Tlatelolco. Through archival research on the signatories of the dedication that precedes these editions of the edifying letter, this study reveals direct links with the efforts to preserve the relative spiritual and economic autonomy of New Spain's indigenous communities in the context of the Bourbon Reforms. This article furthermore demonstrates a sophisticated use of legal discourse and print culture by the indigenous elites of Mexico, who resignified Paredes' hagiographic discourse as a scathing criticism of the abuses suffered by their communities at the hands of local and metropolitan officials.

Key words: New Spain, Bourbon Reforms, jesuits, indigenous communities, hagiography.

\section{INTRODUCCIÓN}

La repentina expulsión de la Compañía de Jesús de la Nueva España en 1767 por orden de Carlos III no puso fin a la publicación de obras devotas escritas por los ignacianos en el virreinato. Como ha señalado Salvador Bernabeu (2009: 1262), el jesuitismo persistió en el virreinato por diversos medios: la impresión y circulación de obras escritas por los miembros de la Compañía, las devociones populares promovidas por la orden, las artes plásticas que representaban a sus miembros canonizados, la literatura de cordel que criticaba la expulsión, y hasta la presencia de un grupo de pícaros que simulaban ser jesuitas clandestinos para aprovecharse de la credulidad de los devotos de la orden. En cuanto a la reedición de obras jesuitas en la Nueva España entre 1767 y 1816, el año de la restauración de la orden en el virreinato, se publicaron más de 300 libros de autoría ignaciana, de los cuales más de $95 \%$ eran devocionarios de reducido tamaño y tosca producción destinados a fomentar el culto a los santos — tanto jesuitas como no jesuitas - y el ejercicio de las virtudes en la vida cotidiana de los diversos sectores de la sociedad novohispana (Medina, 1908, 1910). Una de las obras más notables de este corpus es la Carta edificante en que el P. Antonio de Paredes de la extinguida Compañia de Jesús refiere la vida exemplar de la Hermana Salvadora de los Santos, india otomí, una obra orignalmente publicada en $1762 .{ }^{1}$ Esta obra es excepcional por varios motivos: de un corpus prolífico de obras hagiográficas escritas por los jesuitas del virreinato, es la única que se publicaría después de 1767; el texto relata, además, la vida de una beata otomí de Querétaro que inspiró un culto local a mediados del siglo XVIII; y, finalmente, su reedición en 1784 y 1791 fue subvencionada por las parcialidades indígenas de la Ciudad de México.

\footnotetext{
${ }^{1}$ El título original de la obra es Carta edificante en que el P. Antonio de Paredes de la Compañía de Jesús, da noticia de la exemplar Vida, sólidas virtudes, y santa muerte de la Hermana Salvadora de los Santos, India Otomí, Donada del Beaterio de las Carmelitas de la Ciudad de Querétaro. Se registran ediciones de 1762 y 1763, aunque no existen ejemplares de la primera edición.
} 
El texto de Paredes sobre la vida de Salvadora de los Santos ha sido examinado en varios estudios recientes como ejemplo de la cultura conventual y de la hagiografía femenina escrita por los jesuitas. Según Asunción Lavrín (2008: 253), la obra hagiográfica sobre la donada otomí tenía la intención de demostrar que la gracia divina podía encaminar hasta a los seres menos civilizados hacia la virtud. Antonio Rubial García (2006: 90) señala que en el texto de Paredes se advierte una tendencia en la hagiografía novohispana hacia la representación de sujetos de orígenes humildes con el fin de promover modelos de conducta entre todos los sectores del virreinato. Mónica Díaz (2010: 67-68) lee la Carta edificante como una intervención directa en los debates sobre la fundación de conventos para monjas indígenas en la que la obra de Paredes respaldaría la opinión de que estos eran innecesarios, ya que las mujeres indígenas podrían realizar su vocación religiosa en beaterios, aunque solo fuera en calidad de sirvientas, o donadas, como en el caso de la beata otomí. En la investigación histórica más completa sobre la vida de Salvadora de los Santos Ramírez, Dorothy Tanck de Estrada (2011) nota la excepcionalidad del texto como "the only full-length biography of an Indian written and published in all of the Americas during the colonial period" (76). Con una lectura minuciosa del texto que rescata valiosos detalles históricos sobre el Quéretaro de la época, Tanck de Estrada (2011: 95) vincula la Carta edificante con la promoción de santos americanos entre los criollos novohispanos a mediados del siglo XVIII.

Si por un lado representan un aporte sustancial a nuestra comprensión de la Carta edificante y de su sujeto, las investigaciones de Tanck de Estrada —al igual que los otros estudios recientes de la obra - no indagan sobre las posibles razones que pudieron haber animado a los gobernadores de San Juan Tenochtitlan y Santiago Tlatelolco a subvencionar la reimpresión de esta obra, más allá de la reproducción servil del modelo de conducta indígena promovido por un religioso criollo. Al enfocarse exclusivamente en el uso de la Carta edificante como texto escolar en los colegios indígenas, Tanck de Estrada (2011: 85) imagina una escena pedagógica idealizada dónde los niños indígenas que leían la obra de Paredes como texto escolar "were entertained by [Salvadora's] familiarity with animals, scared by her adventures on the road, impressed by her charitable works, and pleased by her honored place as one of the most outstanding and interesting members of a multiracial society". ${ }^{2}$ El mismo Paredes no pudo haber imaginado una mejor recepción de su obra.

El presente estudio pretende imaginar otras posibles reacciones a la Carta edificante que no se limitan a la reproducción pasiva de la subordinación indígena, tal y como la vergüenza, la indignación, la ira, y hasta la risa al encarar la hipocresía de verse representados como seres cultural, moral e intelectualmente inferiores, cuyo único camino hacia la virtud

\footnotetext{
${ }^{2}$ En Independencia y educación: Cultura cívica, educación indígena y literatura infantil (2013), Tanck de Estrada sintetiza su excelente ensayo sobre Salvadora de los Santos Ramírez (posición 1497). A pesar de ser autora de uno de los estudios más importantes sobre las presiones económicas ejercidas sobre los pueblos de indios en la Nueva España durante los últimos cincuenta años del virreinato (Pueblos de indios y eduación en el México colonial, 1999), Tanck de Estrada no vincula este contexto con la reimpresión de la Carta edificante como una sutil protesta contra las nuevas políticas implementadas por los oficiales virreinales después de 1766 .
} 
era sufrir con paciencia los atropellos cotidianos propinados por una elite criolla y española. Se plantea que la reimpresión de la Carta edificante aprovecha la figura de Salvadora de los Santos Ramírez para esgrimir una crítica mordaz contra la nueva política borbónica de sustraerles donativos a las arcas de las comunidades indígenas novohispanas, ya sea en la forma de tributos o en la forma de imposiciones obligatorias en el recién fundado Banco de San Carlos. Así, la dedicatoria al virrey Matías Gálvez (1717-1784) que acompaña las ediciones de 1784 y 1791, un aspecto paratextual desatendido en los estudios de la obra, se leerá como ejemplo de lo que James Scott (1990: 20) denomina "disguised forms of public dissent", es decir mensajes públicos aparentemente deferenciales respecto a la autoridad, pero que se prestan para una lectura irónica y desestablizadora entre los grupos subordinados. Al seguirles las pistas a los firmantes de la dedicatoria que acompaña las ediciones de 1784 y 1791, se confirma no solo una doble intención en la reedición de la vida de Salvadora de los Santos, sino además un sofisticado uso de la escritura, de la imprenta, y de los géneros jurídico-notariales, mediante el cual se vincula la Carta edificante con la defensa de la autonomía espiritual y económica de las comunidades indígenas durante la segunda mitad del siglo XVIII.

\section{UNA ANACORETA OTOMí REDUCIDA A LA VIDA POLÍTICA}

La obra de Paredes evidencia una profunda ambivalencia hacia Salvadora de los Santos Ramírez en particular y hacia los indígenas del virreinato en general, lo que se observa desde las primeras páginas de la obra al diferenciar entre los indígenas que todavía viven "como bestias" tantos años después de la Conquista y aquellos que "se reducen a la vida política” (1784: 2). El mérito de la beata, según Paredes, fue ejemplificar las virtudes santas a pesar de ser otomí, "los de peor condición" (1784: 2). De este modo, Ramírez se presenta como ejemplo del indígena incorporado a la grey temporal y espiritual de los "reducidos" y su identidad como otomí que nació lejos de los centros urbanos virreinales marca su trayectoria como excepcionalmente ejemplar. Mientras que Paredes afirma que Ramírez había procurado emular a los "Religiosos, o Anacoretas" (1784: 12) antes de radicarse en Querétaro, no alcanzaría la cumbre de las virtudes hasta abandonar su vida itinerante de pastora y vincularse con el beaterio queretano. De este modo, el jesuita lee la vida de Salvadora como el inverso y complemento de la vida del misionero ideal que viaja desde las ciudades al campo para reducir a los que viven "como bestias" e incorporarlos al orden político de la Nueva España. ${ }^{3}$

\footnotetext{
3 "Reducción" denota la forma de gubernamentalidad desarrollada en las Américas a partir del siglo XVI, lo que era un elemento esencial de la vocación que realizaban los misioneros jesuitas en Hispanoamérica. En Política indiana, Juan de Solórzano y Pereira (1648: 203) describe el concepto de reducción a partir del estudio de su implementación heterogénea en las Américas durante el primer siglo y medio de conquista y colonización. En su estudio de los aspectos políticos, espaciales, religiosos, conductuales y lingüísticos de reducción entre los maya durante el Periodo Colonial, William Hanks (2010) explica que "To be reducido was above all to live in
} 
Las cartas edificantes contemporáneas sobre los misioneros jesuitas en Baja California, para aquel entonces el non plus ultra de la frontera misionera novohispana, presentan quizás el mejor contrapunteo para entender la lógica de reducción en el texto de Paredes. ${ }^{4}$ La obra hagiográfica sobre la vida y virtudes apostólicas de Francisco María Piccolo, escrita por Juan Antonio Balthasar (1752), visitador de misiones y provincial de la orden en la Nueva Espańa, describe la trayectoria vital del misionero modelo como el inverso de la vida de Salvadora de los Santos narrada por Paredes. Según Balthasar, el jesuita de origen siciliano abandona la ciudad y la comodidad de los colegios urbanos para inmiscuirse entre grupos nómadas a quienes procura incorporar al orden político y religioso del virreinato:

[...] su principal cuidado, y solicitud se empleó siempre en atender a el fin de las misiones, que es atender a el bien espiritual, doctrina, y enseńanza de los Indios. A los principios convirtió, y baptizó un crecido numero de gentiles; reduciéndolos a vida política, formó con ellos un Pueblo. Esta gentilidad, que reduxo el Apostolico zelo del P. Francisco, estaba escondida en los bosques, y breñas [...] (1752: 32-33).

El misionero ideal y la donada otomí así forman una especie de quiasmo: los jesuitas parten de la ciudad para reducir a los grupos nómadas de la frontera, y Ramírez entra a la ciudad desde el campo para reducirse a la vida política sirviendo a sus hermanas en el beaterio carmelita de Querétaro. La forma quiástica de estos relatos biográficos no solo representa un esquema retórico sino además representa un poderoso modelo conceptual que busca establecer el equilibrio y la armonía en un contexto conflictivo. Según la taxonomía planteada por Anthony Paul, este uso del quiasmo correspondería al "quiasmo de cruce", el que reafirmaría "a solid rightness of relations" ante las disyuntivas éticas y políticas (2014: 25).

Mientras que los misioneros jesuitas como Piccolo y Juan de Ugarte sufrieron su trabajo apostólico en Baja California como "una mortificación continua" digna de los Padres del Desierto, la mayor prueba de Ramírez se enfrentaría en el claustro, donde soportaría como "una mortificación continuada por veinte y seis años" el abuso y desprecio de las criollas a quienes atendía como sirvienta en el beaterio queretano (Villavicencio 1752: 193; Paredes 1784: 65). Paredes explica que el beaterio frecuentemente sufría estrecheces económicas debido al aumento de hermanas y las enfermedades que éstas sufrían, por lo que la donada otomí se vio obligada a salir a buscar limosnas y provisiones para mantener

\footnotetext{
a stable place, in which things were done in their proper settings and people behaved in ways appropriate to those settings. The concept of propriety here derives from policía, itself derived from polis, 'town"' (2). Aunque plantea una distinción júridico-administrativa tajante entre los conceptos de congregación y reducción, ambos empleados para describir una variedad de prácticas desde la sedentarización de grupos semi-nómadas hasta la reubicación de pueblos sedentarios, Amy Turner Bushnell (2004) da una detallada historia de las distintas campañas de reducción emprendidas en Hispanoamérica durante el periodo colonial, en que se destacaron los jesuitas desde el Reino de Chile hasta California.

${ }^{4}$ Para una descripción contemporánea de la vida de los californios como el último escalafón de la vida humana, ver Burriel y Venegas (1757: Vol. 1, 74).
} 
a la comunidad (1784: 46-47). A pesar de servir en el beaterio "como una esclava", el autor jesuita explica que Ramírez tuvo que ejercer una paciencia ejemplar para soportar el abuso y humillación cotidianos propinado por las demás beatas: "Las Hermanas, aunque gente virtuosa, mas como mujeres tienen sus genios unas prolijos, otras violentos, otras ásperos, y si Salvadora alguna vez no acertaba a darles gusto en lo que la mandaban, el desahogo eran regaños, apodos y dichos picantes" (1784: 62).

Al trasladar este ejemplo al contexto de las parcialidades de San Juan Tenochtitlan y Santiago Tlatelolco dos décadas después de su primera edición, no se resaltarán tanto la abnegación y virtudes cristianas de la beata otomí, sino la dependencia económica de las beatas criollas de la mano de obra de Salvadora, y los abusos que ésta sufría a pesar de sus evidentes méritos espirituales e intelectuales. Mientras que Paredes reafirma la lógica de reducción como un estado natural en que los indígenas del virreinato solo podrían alcanzar un estado de virtud a través de su subordinación, la aparición de su libro en un nuevo contexto pondría esa idea en tela de juicio. En lo que sigue demostraré que en este nuevo contexto la vida de la beata otomí se presenta no tanto como un ejemplo a emular, sino como una crítica de los vicios de clases dominantes y las vejaciones cotidianas sufridas por los indígenas del virreinato.

\section{LA “EXTINGUIDA" COMPAÑ́́A Y LA AUTONOMÍA ESPIRITUAL DE LOS PUEBLOS INDÍGENAS NOVOHISPANOS}

Hasta ahora, no se ha prestado suficiente atención a la dedicatoria que precede las reediciones de la obra de Paredes en 1784 y 1791. Si por un lado esta dedicatoria parece reproducir fielmente el modelo de piedad y abnegación que los oficiales eclesiásticos y políticos esperaban inculcar en los sujetos indígenas del virreinato, por otro lado se descubren motivaciones más complejas, y hasta subversivas, cuando leemos este paratexto a la luz del contexto económico, político y cultural de las comunidades indígenas frente a lo que Serge Gruzinski ha denominado la "segunda aculturación" (1985: 192) bajo las Reformas Borbónicas. 5 Como señala Matthew O’Hara, el "registro suplicatorio" (2010: 171) que se evidencia en los documentos y peticiones de los grupos indígenas de la época es frecuentemente una táctica empleada para conseguir algún objetivo concreto. ${ }^{6}$ Quizás nunca sabremos a cabalidad cuáles fueron las intenciones de los gobernantes de Santiago y San Juan al elegir esta obra y dedicarla al Virrey Matías de Gálvez; no obstante, las pistas fragmentarias y dispersas que dejaron en los archivos novohispanos nos permiten conjeturar

\footnotetext{
${ }^{5}$ Aquí aplico la definición elaborada por Gerard Genette (2001) de "paratextos" como aquellos artefactos discursivos y visuales (desde la portada del libro hasta entrevistas con el autor) cuya función es establecer una relación pragmática entre un lector y el texto primario constituido por la obra (8).

${ }^{6}$ Por ejemplo, se evidencia el mismo registro con algunas de las mismas fórmulas en una petición de 1773 firmada por Cosme Miguel de la Mota, el gobernador de San Juan de Tenochtitlan que firma la dedicatoria de las ediciones de 1784 y 1791. Archivo General de la Nación, México, Real Junta, vol. 4066, exp. 24.
} 
un uso sofisticado de la escritura y de la imprenta para reafirmar la autonomía espiritual y económica de su comunidad y reprochar los vicios de los criollos y espańoles del virreinato y de la metrópoli.7 Según reza la dedicatoria,

La reimpresión de esta Carta edificante tiene el objeto recomendable de proveer las Escuelas y Migas donde nuestros hijos son educados de una especie de Cartilla, en que, enseñándose a leer, aprendan al mismo tiempo a imitar las virtudes christianas con el dulce, poderoso, y natural atractivo de verlas practicadas por una Persona de su misma calidad (Paredes 1784).

Si los gobernadores de las dos parcialidades sólo necesitaban una obra que representaba un ejemplo de piedad indígena reconocido por las elites políticas y eclesiásticas de la sociedad novohispana, la obra de Paredes parecería ser una opción idónea; no obstante, la elección de una obra escrita por un jesuita resulta algo extraña dada la "Pragmática sanción" que decretó la expulsión de los ignacianos en 1767, la cual impuso el silencio absoluto sobre cualquier asunto que tuviera que ver con la orden (Novissima 1805: 182). ${ }^{8}$

Por un lado, la obra de Paredes no está dedicada a la vida de un jesuita ni interviene directamente en las polémicas en torno a la expulsión; y cuando las parcialidades indígenas de México-Tenochtitlan publicaron la segunda edición de la Carta edificante en 1784 ya habían transcurrido 17 años desde el extrañamiento de la Compañía, quizás suficiente tiempo para amortiguar el celo de los inquisidores. Así y todo, cabe recordar el apoyo popular hacia los jesuitas ante el edicto de expulsión, lo que valió una dura represión militar liderada por el visitador general, José de Gálvez (1720-1787), el mismo hermano del Virrey a quien iba dirigida la dedicatoria firmada por los gobernadores de San Juan y Santiago. A pesar de la pleitesía de los gobernadores indígenas hacia el Virrey, el subvencionar la reimpresión de una obra escrita por un jesuita novohispano (quien además murió en el puerto de Veracruz junto a 28 de sus correligionarios antes de embarcarse al exilio) podría interpretarse como un acto desafiante que la intercalación de "extinguida Compañía de Jesús" en la portada del libro serviría más para subrayar que atenuar."

\footnotetext{
${ }^{7}$ Por supuesto, estos agentes y los grupos que representaban podían tener motivaciones diversas, complejas y hasta contradictorias. No se pretende "reducir" la agencia subalterna a una voluntad meramente oposicional. El clásico ensayo de Florencia Mallon (1994) sigue siendo una reflexión útil sobre las antinomias inherentes en cualquier abordaje de los grupos subordinados en el contexto colonial de América Latina.

${ }^{8}$ Como ha seńalado Tanck de Estrada (1999), la subvención de un texto escolar por una comunidad indígena fue excepcional, y representaba una enorme ventaja sobre otras comunidades en que los padres de los alumnos tenían que comprar las "cartillas", lo que significaba un impedimento muchas veces insalvable para la escolarización de niños indígenas (406-17).

${ }^{9}$ Paradojalmente, esta referencia a la expulsión representaba una transgresión del silencio absoluto decretado en la "Pragmática sanción" de Carlos III. De los aproximadamente 300 libros de autoría jesuita publicados entre 1767 y 1816 (muchos de los cuales escatiman la afiliación de sus autores) solo cinco hacen referencia a la expulsión en sus portadas (Medina, 1908, 1910).
} 
Más que una particular adhesión a los ignacianos o al concepto de reducción que se alegoriza en el texto de Paredes, la reimpresión de la Carta edificante tiene un vínculo estrecho con otro proyecto de educación apoyado por los gobernadores de San Juan y Santiago, quienes, junto con algunos jesuitas de la capital, revindicaban la autonomía espiritual e intelectual de los indígenas del virreinato. Se trata de la reapertura del Colegio de Santa Cruz de Tlatelolco, fundado originalmente por los franciscanos en el siglo XVI para la formación del clero indígena. Este ambicioso proyecto fue iniciado en 1753 desde Madrid por Julián Cirilo de Castilla Aquinahual Cateuhtle, un sacerdote y descendiente de la nobleza tlaxcalteca. En 1754, Andrés Ignacio Escalona y Arias Acxayacatzin y Temilo, clérigo presbítero de la capital y descendiente de la nobleza tlatelolca, se unió al proyecto de Cirilo de Castilla con una solicitud dirigida a Fernando VI (r. 1746-1759), la que desplegó varios argumentos a favor de la educación de los sujetos indígenas del virreinato y la formación de sacerdotes y misioneros indígenas que pudiesen atender a las necesidades espirituales de sus pares (Alberro, 2013: 222-37). En estos documentos, los argumentos a favor de las virtudes espirituales e intelectuales del indígena también dan cuenta de la falta de estas mismas virtudes entre los españoles y criollos del virreinato. Escalona explica que una adecuada educación y el conocimiento de sus derechos ayudarían a proteger a los indígenas del virreinato de las muchas vejaciones que sufren,

por que todos están inbentando trasas, astucias, fraudes, y tretas; con que beberle la sangre de sus benas, a estos Pobres miserables Naturales de este Reino; suspenden, la Justicia, y derecho, a la que pertenece; sofocan, los recursos, a los que les conbiene; atemorizan e imponen miedos, y amenazas los que tienen derecho en los probechos, o aprobechamientos, para el maior remedio de sus necesidades. ${ }^{10}$

En 1755 los gobernadores de Santiago y San Juan se sumarían a la iniciativa con un auto apoyando la reapertura del colegio, el que llevaba la firma de Ignacio de San Roque y Martínez, gobernador de Santiago y el padre de uno de los futuros signatarios de la dedicatoria incluida en las dos reediciones de la Carta edificante. ${ }^{11}$ A diferencia del modelo de conducta que se propone en el libro de Paredes, este proyecto entiende la educación como resistencia, no como un acto de sumisión.

En 1757, Juan Mayora (1710-1762), el rector del colegio jesuita de San Gregorio, el que se dedicaba a la educación de la nobleza indígena de la capital, elaboró un extenso informe en el que apoyó los argumentos a favor del proyecto de Cirilo de Castilla, en contra del parecer del fiscal de la Real Audiencia de la Nueva España, Luis Francisco Mosquera y Pimentel, el marqués de Aranda. Mayora destacó los frutos del Colegio de San Gregorio y la congregación de la Buena Muerte, dos proyectos bajo el patrocinio de los jesuitas y dirigidos a los indígenas de la capital, y refutó la opinión del fiscal de que los indígenas eran

\footnotetext{
${ }^{10}$ AGN, México, Indiferente Virreinal, caja 1311, exp. 27, 8r.

${ }^{11}$ Archivo General de Indias, Sevilla. México, 1937 [microfilm], 101r-102r.
} 
más susceptibles a la pereza, la lujuria y la embriaguez, y por tanto incapaces de ejercer el sacerdocio. Respecto a la supuesta pereza de los indígenas, el jesuita alude a la dependencia de los criollos y espańoles de su mano de obra, e ironiza: "miserables de nosotros si los Indios que son los que llevan el peso de todo lo mecánico en esta Nueva España, se dieran a la ociosidad". ${ }^{12}$

Tras la extinción de la Compañía, Carlos III donaría el colegio de San Gregorio y el Claustro de San Pedro y San Pablo, ambos pertenecientes a la orden, para albergar el nuevo seminario de sacerdotes indígenas. ${ }^{13}$ Existe además un vínculo directo entre este proyecto y la posterior reedición de la Carta edificante. Los autos presentados al rey en nombre de las parcialidades indígenas de la Nueva Espańa de 1770 y 1771, en que sus gobernantes le agradecen al soberano su decreto aprobando la reapertura de Santa Cruz de Tlatelolco, están firmados por los dos gobernadores que luego reeditarían la obra de Paredes en 1784: Juan Ignacio de San Roque y Martínez y Cosme Miguel de la Mota. Se podría interpretar esta iniciativa como una continuación del proyecto jesuita, aunque ahora sin el tutelaje de los ignacianos.

Como miembros de la elite indígena de México-Tenochtitlan, es muy probable que de la Mota y San Roque Martínez hubieran estudiado en el Colegio de San Gregorio, y existen documentos que demuestran que mantuvieron vínculos estrechos con el colegio tras la expulsión. En 1773, de la Mota firma una petición de la Congregación del Colegio de San Gregorio de Indios Caciques y Principales en la que se protesta el traslado de la imagen de Nuestra Señora de Loreto al Convento de la Encarnación. Esta medida fue implementada por los reformadores borbónicos para mermar la influencia de las advocaciones y congregaciones promovidas por los jesuitas, pero los indígenas de la capital virreinal lo vieron como un expolio de su patrimonio cultural y material. En sus peticiones, los gobernadores de Santiago Tlatelolco y San Juan Tenochtitlan insisten en que fueron los mismos indígenas quienes fundaron la iglesia y seminario de San Gregorio antes de la llegada de los jesuitas y que tenían "incontestable derecho a la Casa, y por consiguiente de la Santa Imagen donada a ella”. ${ }^{14}$ En estos documentos, el Colegio de San Gregorio no se presenta como un proyecto jesuita (tal como se representa en los escritos de la orden), sino como un proyecto indígena al que contribuyeron los ignacianos y que debería ser custodiado por sus verdaderos propietarios tras la expulsión. Esta reapropiación y resignificación del patrimonio indígena en el contexto de una reivindicación de su autonomía espiritual y concomitante crítica de la elite criollo-española nos obliga a reinterpretar la Carta edificante de Paredes desde el contexto de su reedición.

Si a la postre el proyecto de seminario para la formación de sacerdotes y misioneros indígenas nunca se materializaría debido a la falta de financiamiento y un contexto político

${ }^{12}$ AGI, Sevilla. México, 1937 [microfilm], 251v. Ver también Alberro (2013: 311).

${ }^{13}$ Ibid., 840r.

${ }^{14}$ AGN, México, Real Junta, vol. 4066, exp. 24, 5r. 
y eclesiástico cada vez más hostil hacia los pueblos originarios, estos documentos, como señala Solange Alberro, dan cuenta del "despertar de un proceso identitario indígena" (2013: 211) durante la segunda mitad del siglo XVIII. En particular, los autos firmados por los gobernadores de Santiago y San Juan reflejan un sofisticado uso de los discursos legales y un cosmopolitismo intelectual sorprendente; además, incluyen una no muy bien velada crítica de las condiciones morales e intelectuales de sus guías espirituales de origen europeo. Más que una particular adhesión a los ignacianos, este contexto nos permite leer la reedición de la Carta edificante como una afirmación de la autonomía de las comunidades indígenas y una provocación a los reformadores borbones que buscaban estrechar los lazos entre estas y el estado espańol.

\section{La deuda metropolitana en el archivo de Santiago y San Juan}

Para mejor comprender la reedición de la Carta edificante como un discurso disfrazado, hay que indagar sobre el segundo motivo aducido en la dedicatoria al Virrey Matías de Gálvez: la inversión de 20,000 pesos de las arcas comunales de San Juan Tenochtitlan y Santiago Tlatelolco en el recién fundado Banco Nacional de San Carlos, el primer banco nacional de España. La mención de esta inversión pone en duda la sinceridad de la dedicatoria como una performance fidedigna del modelo de sumisión y abnegación que los españoles y criollos esperaban en sus interacciones con los indígenas. Esta referencia a la tributación impuesta a los pueblos indígenas del virreinato en el texto que precede la obra de Paredes inevitablemente pone de relieve los sacrificios de Ramírez ante las estrecheces del beaterio queretano. Como señala Carlos Marichal (1990: 106-11), los llamados "donativos graciosos" solicitados para financiar las guerras de España entre 1781-1784 resultaban ser una especie de doble tributación para los sectores populares del virreinato, y fueron especialmente onerosos para las comunidades indígenas. La innovación de la hacienda real en 1782 fue la creación del Banco Nacional de San Carlos y la venta de acciones con el pago de réditos anuales para solventar la deuda externa de la metrópoli. En principio, la imposición de los capitales de sus arcas comunales indígenas en el Banco de San Carlos sería más ventajosa que la extracción de donativos, los cuales representaban una forma de tributación extraordinaria sin el pago de réditos ni la devolución del principal. Esta es la inversión a que los gobernadores de San Juan y Santiago se refieren en su dedicatoria al virrey.

En la dedicatoria, los signatarios agradecen la oportunidad de comprobar su fidelidad al virrey y al monarca espańol, y además destacan la generosidad del rey por haber suspendido el gravamen cobrado a dinero remitido a España desde las Américas. Estas declaraciones de fidelidad, sin embargo, no están exentas de ambivalencia, e inclusive ironía. En su estudio del Banco Nacional de San Carlos y las comunidades indígenas de la Nueva España, José Antonio Calderón Quijano (1962:30) ha demostrado cómo los representantes del estado español recurrieron a medidas coactivas para obtener estas inversiones, las cuales representaban una nueva política paternalista que consideraba los indígenas como sujetos 
incapaces de controlar su propio capital. ${ }^{15}$ Durante las últimas dos décadas del siglo XVIII, la corona seguiría explotando estos capitales, lo que provocaría una aguda crisis económica en las comunidades que dependían de estos fondos para enfrentar malas cosechas y epidemias (Marichal 1990: 137).

Por un lado, las parcialidades de San Juan y Santiago eran las más solventes de la Nueva Espańa, lo que se puede apreciar por el monto de su inversión. ${ }^{16}$ Por otro lado, sufrían las mismas presiones económicas que aquejaban las otras comunidades indígenas novohispanas: la diminución de la población tributaria, el desmoronamiento de su infraestructura, epidemias periódicas, litigios costosos, y el cobro de tributos atrasados (Gibson, 1996: 404). Como señala Calderón Quijano (1962: 114-129), los réditos prometidos se pagaron parcial e irregularmente, y al final la supuesta inversión se convertiría en un impuesto más. ${ }^{17}$ Dado este contexto, es muy probable que la reedición de la Carta edificante en 1791 tuviera menos que ver con la vida ejemplar de la beata otomí y más con el contenido de la dedicatoria, la cual serviría para recordar la deuda contraída con las parcialidades de Santiago y San Juan y el incumplimiento de parte del Banco de San Carlos.

Frente a estas presiones económicas cada vez más onerosas, resulta extraña la expresión del "júbilo y gratitud de que fuimos inundados" por ser obligados a imponer un monto considerable de sus arcas en el Banco de San Carlos. Además, esta mención de la inversión en el Banco de San Carlos -lo que esencialmente representaba otro tributo pagado por los indígenas de la Nueva España para evitar una crisis económica en la metrópoli- enmarca una obra que exalta las virtudes ascéticas de una beata indígena que se vio obligada a mantener a sus hermanas criollas empobrecidas y enfermizas con las limosnas que recolectaba fuera del beaterio. Si los vasallos indígenas de México tendrían que identificarse con la beata otomí, esto implicaría que a la corona le tocaba el papel de las paupérrimas beatas enclaustradas que dependían de sus labores para sobrevivir. De este modo, el estado natural representado en

\footnotetext{
${ }^{15}$ Hay un vívido testimonio del alcalde mayor de Acayucan, Veracruz de 1785 que describe cómo se aprovechaba la solicitud de imposición en el Banco de San Carlos para desfalcar los fondos de las arcas comunales indígenas. AGN, México. Indiferente Virreinal, caja 4848, exp. 7, 2r-2v. Las cajas de comunidad y la relativa autonomía económica de las parcialidades fueron una de las primeras preocupaciones de José de Gálvez tras la expulsión de los jesuitas y la represión de las subsiguientes sublevaciones populares. En 1770, el visitador general solicitó un examen minucioso de los bienes de comunidad y fuentes de ingresos de todos los pueblos de indios del virreinato. AGN, México. Real Hacienda, Bienes de Comunidad, vol. 7, exp. 7.

${ }^{16}$ Sólo la contribución de todas las comunidades indígenas de Oxacaca (19,025 pesos) se aproximó a la de Santiago y San Juan, la cual representaba un 22\% del total recaudado en 1784 de las arcas de comunidad de los pueblos de indios. AGN, México. Indiferente Virreinal, caja 2577, exp. 3.

${ }^{17}$ Por ejemplo, los dividendos de 1784 y 1785 no se pagaron hasta 1786, los de 1786 y 1787 no se pagaron hasta 1789, y los de 1789 nunca llegaron. Los primeros dos ańos se pagó un dividendo de aproximadamente $10 \%$ sobre el principal, lo que pudo haber sido una muestra de buena fe de parte del banco. No obstante, la taza disminuyó considerablemente en los años subsiguientes, oscilando entre el 3 y 5\%. De 1784 hasta 1800, el último año en que se depositaron los réditos en las arcas de comunidad de Santiago y San Juan, se pagó un total de 18.100 pesos; es decir, las parcialidades ni siquiera recuperaron el principal invertido. AGN, México. Indiferente Virreinal, caja 2577, exp. 11, 8r-9r.
} 
la obra de Paredes se trastoca: lo que se presentaba en primeria instancia como una alegoría de la reducción política y espiritual del indígena se convierte en una crítica mordaz de las políticas borbónicas y el expolio de las arcas de las comunidades indígenas.

\section{5. “COMO cosa nUESTRa y no COMO COSA EXTRANAa”}

En lo que sigue me enfocaré en algunas fuentes relacionadas con la gestión de Juan Ignacio de San Roque Martínez como gobernador y alcalde presidente de Santiago Tlatelolco, a fin de explorar el contexto social y económico de la reedición de la Carta edificante. Estos documentos revelan las presiones económicas que sentían las parcialidades de Santiago y San Juan bajo las Reformas Borbónicas, y nos permiten ver al gobernador como un competente y pertinaz mediador entre los intereses de su comunidad y los de los españoles y criollos de la Nueva España. Las experiencias de San Roque Martínez además permiten sustentar la lectura de la reedición de la Carta edificante como un gesto de doble intención. Estos documentos demuestran la estrecha relación entre la relativa autonomía económica de la parcialidad y la defensa de la autonomía espiritual e intelectual de los indígenas que se plantea en los escritos relativos a la reapertura del Colegio de Santa Cruz Tlatelolco. En particular, este caso nos permite apreciar las "trasas, astucias, fraudes, y tretas" que, según Escalona Acxayacatzin y Temilo, los españoles y criollos empleaban para "beberle la sangre de sus benas, a estos Pobres miserables Naturales de este reino". ${ }^{18}$ Como se ha visto, la defensa de las aptitudes espirituales del indígena conllevaba un reproche implícito de los que se consideraban sus superiores.

Un legajo de 1771 detalla las negociaciones entre San Roque y Martínez y los postores para el arrendamiento de la hacienda de Santa Ana, una importante fuente de ingresos para la parcialidad de Santiago. ${ }^{19}$ Aduciendo el deterioro de la hacienda de Santa Ana debido a la entrada de agua salitrosa del lago Texcoco, el primer postor, don Joseph Joaquín Profano y Mudarra, ofreció pagar 1000 pesos anuales, 2000 menos de los pagados por el arrendatario anterior. Ante este desmedro en el presupuesto de la parcialidad, San Roque y Martínez, junto con los demás alcaldes de Santiago y sus parcialidades anexas, rechazó la oferta. En una extensa declaración, el apoderado de las parcialidades - Francisco Fernández de Córdoba - explica la renuencia del gobernador y demás representantes de Santiago a arrendar la hacienda, dado que uno de los arrendatarios anteriores había aprovechado varias artimańas legales para suspender el pago del arriendo durante cuarenta años. Tras no

\footnotetext{
${ }^{18}$ AGN, México. Indiferente Virreinal, caja 1311, exp. 27, 8r.

${ }^{19}$ Gibson interpreta esta disputa principalmente como un conflicto entre el cabildo de la Ciudad de México y la parcialidad de Santiago Tlatelolco, en que el cabildo buscaba poner en entredicho los títulos de la hacienda a fin de vender o arrendar la propiedad a nombre de la ciudad de espańoles (1996: 379). Este legajo revela que se trataba más bien de un conflicto entre un criollo particular y los gobernadores de Santiago, quienes junto con sus representantes del Juzgado General de Naturales emprendieron una defensa de los derechos de la comunidad sobre una propiedad que era de vital importancia para su economía.
} 
percibir ninguna utilidad durante cuatro décadas, las parcialidades recibieron la hacienda del siguiente arrendatario en un estado tan decadente que no se podía aprovechar ni para cultivos ni para el pastoreo de ganado. El apoderado explica que, gracias a los esfuerzos de San Roque y Martínez, se había logrado rehabilitar la hacienda con un nuevo sistema de acequias y que las utilidades actuales sobrepasaban los 2000 pesos, por lo que no convenía arrendar el terreno por un monto considerablemente inferior y a un postor que inevitablemente buscaría maximizar la renta a corto plazo en desmedro de su sustentabilidad. ${ }^{20}$

Este rechazo no hizo desistir a Profano; al contrario, parece haber encendido más su interés en adquirir la hacienda. El postor y sus abogados acusaron directamente a San Roque y Martínez de querer demorar la subasta con "frívolos pretextos" a fin de aprovechar la última cosecha, acusación que resulta absurda dado que la comunidad tenía todo derecho a usufructuar de una hacienda que pertenecía a sus bienes de comunidad y que no tendrían que arrendar ni vender a nadie contra su voluntad. ${ }^{21}$ Ante esta resistencia, Profano intentó prolongar el litigio para obligarle a la parcialidad a incurrir en gastos legales, ante los cuales tendría que ceder eventualmente a su petición. ${ }^{22}$ Ambos lados se acusaron de malicia, y las declaraciones terminaron en ataques personales e insinuaciones sobre la conducta personal del postor y de los representantes de la parcialidad. El abogado de Profano le entregó directamente a San Roque y Martínez un documento en que acusaba al escribano del Juzgado General de Naturales de engañar al gobernador con el fin de seguir disfrutando el tercio de las rentas que recibía gracias a su ayuda con la administración e inversión personal en las mejoras de la hacienda. ${ }^{23}$ Sobre el mismo documento, San Roque y Martínez escribe una respuesta al postor que desestima las acusaciones y expresa su indignación de ver su competencia y probidad cuestionadas, por lo que reafirma su esfuerzo por restaurar la propiedad y declara tajantemente que se trata de un asunto que dependía de la voluntad de los habitantes de Santiago Tlatelolco: "no consentimos ni los hijos de la Parcialidad en tal arrendamiento y mas quando baja de Precio, contra nuestra voluntad y en la presente ocasión estamos atendiendo y mirando como cosa nuestra y no como cosa extrańa para no experimentar maiores destrucciones". ${ }^{24}$ Esto constituye un texto excepcional y revelador, en que la voz del gobernador no está filtrada por su apoderado, abogados o escribanos, y evidencia las aptitudes de San Roque y Martínez como gobernador.

\footnotetext{
${ }^{20}$ AGN, México. Indiferente Virreinal, caja 6224, exp. 16, 17v-18r.

${ }^{21}$ Ibid., 13 r.

${ }^{22}$ Ibid., $45 \mathrm{v}$.

${ }^{23}$ El tercio de Moreno del Castillo se deducía de una renta bruta anual de más de 3000 pesos. El escribano invirtió más de 5000 pesos de su propio caudal, junto con 950 del caudal personal de San Roque y Martínez, para rehabilitar la hacienda, por lo que se entiende mejor cómo se aunaban los intereses económicos de los representantes del Juzgado General con los de los gobernadores de Santiago. Así y todo, una revisión exhaustiva de las cuentas de la parcialidad por parte de un contador nombrado por el Virrey confirmó la probidad del escribano y de San Roque y Martínez en su administración de la hacienda. AGN, México. Indiferente Virreinal, caja 6224, exp. 16, 32v-32r.

${ }^{24}$ AGN, México. Indiferente Virreinal, caja 6224, exp. 37v.
} 
Al final, la parcialidad se vio obligada a aceptar la postura de Francisco López, vecino del Santuario de Nuestra Señora de Guadalupe y residente de la Ciudad de México, quien ofreció arrendar la hacienda en 2305 pesos al año por cinco años, con el compromiso de depositar la tercera parte del arriendo por adelantado y comprar al contado el ganado y demás bienes (muebles, aperos, y siembras) que se encontrasen en la hacienda al momento de entregársela. Esta oferta no sólo mejoró bastante las condiciones propuestas por Profano, sino que también le permitió a San Roque y Martínez dar fin a los interminables litigios iniciados por postores inescrupulosos que buscaban usufructuar de la Hacienda de Santa Ana bajo condiciones claramente desfavorables para la parcialidad. ${ }^{25}$

El legajo sobre el arriendo de Santa Ana revela la precariedad de los bienes de comunidad de las parcialidades, las cuales requerían una eficaz administración y una tenaz defensa contra criollos y españoles que procuraban apropiarse de ellos. Como gobernador de Santiago, San Roque y Martínez no sólo tendría que lidiar con individuos que buscaban usufructuar de los bienes de su comunidad, sino que también tendría que enfrentar grupos más poderosos. En 1787, entre la primera y segunda reedición de la Carta edificante, el cabildo de la Ciudad de México inició una demanda para que las parcialidades comenzaran a pagar el llamado "real de policía", un impuesto que se cobraría a cada sujeto indígena para financiar obras públicas en la ciudad de españoles. Esta contribución, argumentó el representante del cabildo, fue suspendida excepcionalmente en 1737 por el virrey debido a la epidemia del ańo precedente, pero las parcialidades no habían vuelto a pagar el tributo durante medio siglo.

La demanda del cabildo de la Ciudad de México fue rechazada por don Manuel Lucio Basail, el apoderado general del Juzgado General de Naturales, quien representaría a San Roque y Martínez y los demás gobernadores de las parcialidades ante la Real Audiencia durante diez ańos. Desde un comienzo, el tenor de los documentos se vuelve contencioso, y los autos presentados por ambas partes desestiman con ironía los argumentos esgrimidos por su contraria. En su primera respuesta, por ejemplo, Basail destaca lo absurdo de la demanda, ya que el cabildo confiesa no contar con documentación para respaldar su demanda y exige que las parcialidades produzcan evidencia de que estaban eximidos de pagar un tributo que no pagaban. ${ }^{26}$ En sus respuestas, los representantes del cabildo argumentan que aunque los habitantes de las dos parcialidades no hubiesen pagado el real de policía durante cien años, igual estaba conforme con derecho que contribuyeran con las obras públicas y limpieza de la ciudad española, lo que también les beneficiaría a ellos, un beneficio que los representantes de las parcialidades luego pondrían en entredicho con muy sólidos argumentos. ${ }^{27} \mathrm{El}$ abogado del cabildo, quizás preparado para un litigio que duraría ańos, solicitó que las parcialidades comenzaran a depositar el real de policía antes de salir el fallo, a fin de evitar que invocaran

\footnotetext{
${ }^{25}$ AGN, México. Indiferente Virreinal, caja 6224, exp. 16, 83r.

${ }^{26}$ AGN, México. Indiferente Virreinal, caja 5178, exp. 25, 3v.

${ }^{27}$ Ibid., 7r, 121r.
} 
su pobreza como pretexto para no pagar los tributos atrasados en caso de que se fallara a favor de la ciudad. ${ }^{28}$ Esto habría constituido otro tributo gravoso para las parcialidades, el cual se sumaría a los donativos sustraídos de sus arcas para financiar las guerras de España.

A medida que se prolongaba la demanda y la oposición de las parcialidades, los autos presentados no sólo se limitan a presentar argumentos jurídicos, con abundantes referencias a la obra del jurista Juan de Solórzano y Pereira (1575-1655), sino que también aducen evidencia del archivo histórico sobre la Conquista e incluso de la época prehispánica. El apoderado de las parcialidades, por ejemplo, cita "uno de los mejores cronistas, o historiadores de la Conquista de este Reyno" para demostrar que Carlos V siempre quiso proteger a sus vasallos indígenas del pago de tributos excesivos. ${ }^{29}$ Los representantes del cabildo responden que los habitantes de Tenochtitlan antes de la Conquista estaban sujetos a muchas formas de tributación,

entre las quales no era la menor la del tributo de todas aquellas doncellas, que pareciéndoles bien parecidas a los Ministros del Emperador las recojían, y separándose del lado de sus Padres las trayan a su elección para las que le agradaran quedaron en su servicio en calidad de concubinas. ${ }^{30}$

Dados estos antecedentes, argumentan que los habitantes indígenas de MéxicoTenochtitlan no sólo estaban acostumbrados a pagar tributos, sino que también los que el cabildo pretendía cobrar resultarían ser exiguos en comparación con la tiranía bajo la cual vivían en "su gentilidad". Refutar esto, según los representantes del cabildo era "una audacia ciertamente digna de la más seria reprensión" ${ }^{31}$ En estas interpretaciones cruzadas sobre la historia de la Conquista, en las cuales se disputan las categorías raciales imperantes y los derechos y deberes que estas implican, podemos apreciar cómo el archivo colonial funciona menos como un repositorio de hechos que fija el poder, y más bien, como señala Ann Laura Stoler (2009: 32-33), un espacio donde las categorías que estructuran la realidad social son interpretadas, negociadas y disputadas entre diversos actores. ${ }^{32}$

\footnotetext{
${ }^{28}$ Ibid., 8v-9r.

${ }^{29}$ Ibid., 23 r.

${ }^{30}$ Ibid., 28v-29r.

${ }^{31}$ Ibid., 31v.

${ }^{32}$ En este sentido, son notorias las interpretaciones del "idiotismo" de los indígenas que se esgrimen en los documentos relativos a la demanda del cabildo contra las parcialidades de Santiago y San Juan. Los abogados de las parcialidades arguyen que debido al "idiotismo" -un concepto jurídico homólogo a la minoría de edadel haber pagado el "real de policía" en el pasado no representa un reconocimiento de su obligación de pagar dicho tributo. Por su parte, los abogados del cabildo plantean que el acogerse a dicho concepto es un artilugio cínico, ya que no aplica en el caso de "Indios tan civilizados, como lo son los de que se trata". Paradojalmente, los sujetos indígenas y sus representantes en el Juzgado General invocan su subordinación institucionalizada, mientras sus contrarios abogan por su igualdad ante la ley. Ibid., 21v, 33v.
} 
Con la ayuda de sus representantes del Juzgado General, las parcialidades pudieron posponer el pago del real de policía durante dos décadas mediante lo que un abogado del cabildo calificó de "pretextos, ardides y subterfugios". ${ }^{33}$ Al final, José Manuel Vallarta, el solicitador del Juzgado General que asumió el caso después de Basail, demostró que entre 1787, el ańo en que se inició la demanda, hasta 1804, el último año en que habían realizado un censo de los tributarios de San Juan y Santiago, las dos parcialidades habían gastado de sus arcas 24.724 pesos en obras públicas, 4.719 pesos más de lo que tendría que haber pagado mediante el real de policía para los mismos fines. El abogado arguye audazmente que sus partes no sólo no debían nada al cabildo, sino que además se les tendría que devolver los 4.719 pesos que habían tributado en exceso durante este periodo. ${ }^{34}$ El legajo sobre esta demanda termina en 1806 con este argumento fulminante, y al parecer los representantes del cabildo desistieron ante la idea de extender un litigio que ya había durado casi dos décadas y que no prometía rendir ningún resultado favorable a sus partes.

Estos documentos nos permiten ver a los gobernadores de Santiago y San Juan como agentes activos y hábiles, que defendían los intereses de su comunidad ante varios actores y que lucharon por mantener la relativa autonomía económica y espiritual de las comunidades indígenas frente al ímpetu homogeneizador de las Reformas Borbónicas. Juan Ignacio de San Roque y Martínez acumuló décadas de experiencia resistiendo a hacendados y oficiales locales, quienes, por avaricia, necesidad o un espíritu paternalista buscaban apropiarse de los bienes de las parcialidades indígenas de México. Desde luego, fue más fácil resistir la voluntad de las autoridades locales que la del soberano y sus representantes en el virreinato, por lo que sólo le quedaba un recurso a los gobernadores de San Juan y Santiago: acceder a la solicitud de imposición de sus fondos en el Banco de San Carlos mediante un mensaje público que de modo muy sutil recordara al rey, al virrey y a las generaciones venideras de las parcialidades de que fueron los pueblos indígenas de la Nueva España -los vasallos más humildes del soberano- quienes acudieron ante la necesidad urgente de la metrópoli. Tras una vida dedicada a defender los caudales acumulados y mantenidos gracias al sacrificio de su comunidad y la eficaz administración de sus gobernantes, es impensable que a San Roque y Martínez no se le haya ocurrido el paralelo con la historia de la beata otomí de Querétaro que se vio obligada a mantener a sus hermanas inertes y malagradecidas.

\section{Conclusión}

Leído en el contexto de la lucha por la autonomía económica, intelectual y espiritual de las parcialidades indígenas de la Nueva España durante la segunda mitad del siglo XVIII, es posible ver la Carta edificante de Paredes como otro tipo de texto pedagógico: ya no como una obra destinada a inculcar la sumisión y abnegación en los alumnos que

\footnotetext{
${ }^{33}$ Ibid., $104 \mathrm{r}$.

${ }^{34}$ Ibid., 119v.
} 
aprenderían a leer con la ayuda de esta "cartilla", sino como un discurso disfrazado que fomentaría una mirada crítica que reafirmara la superioridad intelectual y moral de los subordinados. Esto sería un ejemplo de lo que Scott (1990: 79) llama la "mala lectura" (misreading) de la hegemonía realizada por grupos subordinados, la cual termina, a la postre, desnaturalizando la dominación. Este caso implica un hábil y sofisticado uso de la cultura escrita y de la imprenta, además de una comprensión penetrante de las aporías inherentes del archivo colonial. La reedición de la Carta edificante, junto con hábil manejo de la cultura jurídico-notarial, representan un caso de lo que Joanne Rappaport y Tom Cummins (2012: 10) denominan la "inter-cultura manuscrita" mediante la cual los grupos subalternos intervienen en el archivo para negociar y resistir las categorías impuestas por el discurso colonial. A diferencia de los casos examinados por Rappaport y Cummins, los líderes de las parcialidades de San Juan y Santiago lograron penetrar el espacio de la cultura impresa, aunque solo fuera mediante la reedición de una obra hagiográfica jesuita con una dedicatoria que, leída en el contexto novohispano durante las últimas décadas del siglo XVIII, ofrece un mensaje público y disfrazado que conlleva una crítica mordaz de las clases dominantes del virreinato.

Al consignar la Carta edificante a los "Hijos de nuestros Nietos, Generaciones distantes que nosotros no hemos de ver", los gobernadores de San Juan y Santiago evidenciaron una conciencia aguda de las antinomias inherentes en el concepto de archivo: el pasado y el futuro, lo arcano y lo transparente, lo privado y lo público, o el evento y su interpretación (Derrida, 1997: 98). Su discurso disfrazado permanece inmiscuido en el archivo colonial y a la vez sustraído de él; representa una proyección mesiánica hacia un futuro en que su interpretación cabal podría dar inicio a un nuevo orden social. Tanto la vida de Salvadora de los Santos Ramírez, con su muy hábil adaptación de modelos tradicionales de santidad, como la resignificación de su hagiografía en el marco de un discurso disfrazado que pone en tela de juicio la dominación espańola, sugieren un sofisticado uso del archivo y de sus soportes materiales por parte de los indígenas de la Nueva España y nos obligan a imaginar otras lecturas de los discursos coloniales que no se limiten al paradigma de la reproducción ideológica.

\section{Obras Citadas}

Alberro, Solange. 2013. "Los Indios y los otros: Miradas cruzada. Tlaxcala, México, Madrid, 1753-1779". En La sociedad novohispana: estereotipos y realidades, Solange Albero y Pilar Gonzalbo. México: El Colegio de México. 195-362.

Balthassar, Juan Antonio. 1752. Carta que da noticia de la exemplar vida, religiosas virtudes, y apostólicos trabajos del ferveroso Missionero el Venerable P. Francisco Maria Picolo. México: n.p.

Bernabéu Albert, Salvador. 2009. "El vacío habitado. Jesuitas reales y simulados en México durante los años de supresión (1767-1816)”. Historia Mexicana, 58.2: 1261-1303. 
Burriel, Andrés Marcos y Miguel Venegas. 1757. Historia de la California y su conquista temporal y espiritual hasta el tiempo presente. Madrid: En la imprenta de la viuda de M. Fernández y del Supremo Consejo de la Inquisición.

Calderón Quijano, José Antonio. 1962. "El Banco de San Carlos y las comunidades de indios de Nueva España". Anuario de Estudios Americanos 19: 1-144.

Castro Gutiérrez, Felipe. 1996. Nueva ley y nuevo rey: Reformas borbónicas y rebelión popular en Nueva España. Ciudad de México: Universidad Nacional Autónoma de México, Instituto de Investigaciones Históricas.

Derrida, Jacques. 1997. Mal de archivo. Una impresión freudiana (P. Vidarte, trans.). Madrid: Trotta.

Díaz, Mónica. 2010. Indigenous Writings from the Convent: Negotiating Ethnic Autonomy in Colonial Mexico. University of Arizona Press.

Genette, Gerard. 2001. Umbrales (Susana Lage, trans). México: Siglo Veintiuno Editores.

Gibson, Charles. 1996. Los Aztecas bajo el dominio español, 1519-1810 (J. Campos, trans.). México: Siglo Veintiuno Editores.

Gruzinski, Serge. 1985. "La 'segunda aculturación': El estado ilustrado y la religiosidad indígena en Nueva España (1775-1800)". Estudios de Historia Novohispana 8.8: 175201.

Hanks, William. 2010. Converting Words. Maya in the Age of the Cross. Berkeley: University of California Press.

Lavrín, Asunción. 2008. Brides of Christ: Conventual Life in Colonial Mexico. Stanford University Press.

Mallon, Florencia. 1994. "The Promise and Dilemma of Subaltern Studies: Perspectives from Latin American History." The American Historical Review 99.5: 1491-1515.

Marichal, Carlos. 1990. "Las guerras imperiales y los préstamos novohispanos, 1781-1804". Historia Mexicana 39.4: 881-907.

Medina, José Toribio. 1908. La imprenta en Puebla de los Ángeles. Santiago de Chile: Imprenta Cervantes.

1910. La imprenta en México, 8 vols. Santiago de Chile: Impresa en la Casa del Autor.

Novissima recopilación de las leyes de España. 1805. Madrid: n.p.

O'Hara, Matthew. 2010. A Flock Divided: Race, Religion, and Politics in Mexico, 17491857. Durham: Duke University Press.

Paredes, Antonio de. 1784. Carta edificante en que el P. Antonio de Paredes de la extinguida compañia de Jesus refiere la vida vida exemplar de la hermana Salvadora de los Santos, Indio Otomi, que reimprimen las parcialidades de S. Juan y de Santiago de la capital de Mexico. Reimpressa en Mexico: En la imprenta nueva Madrileña de los herederos del Lic. D. Joseph de Jauregui, en la Calle de San Bernardo.

Paul, Anthony. 2014. "From Stasis to Ékstasis: Four Types of Chiasmus." En Anthony Paul y Boris Wiseman, Eds. Chiasmus and Culture. New York: Berghahn:19-44.

Rappaport, Joanne and Tom Cummins. 2012. Beyond the Lettered City: Indigenous Literacies in the Andes. Durham: Duke University Press. 
Rubial García, Antonio. 2006. Profetisas y solitarios: espacios y mensajes de una religión dirigida por ermitaños y beatas laicos en las ciudades de Nueva España. México: Universidad Nacional Autónoma de México; Fondo de Cultura Económica.

Scott, James. 1990. Domination and the Arts of Resistance: Hidden Transcripts. New Haven: Yale University Press.

Solórzano Pereira, Juan de. 1648. Política indiana. Madrid: Por Diego Díaz de la Carrera.

Stoler, Anne Laura. 2009. Along the Archival Grain: Epistemic Anxieties and Colonial Common Sense. Princeton: Princeton University Press.

Tanck de Estrada, Dorothy. 1999. Pueblos de indios y educación en el México Colonial, 17501821. México: El Colegio de México, Centro de Estudios Históricos. . 2011. "Who was Salvadora de los Santos Ramírez, Otomí Indian?”. En S. Slater y F. A. Yarbough, Eds., Gender and sexuality in Indigenous North America, 1400-1850. Columbia: University of South Carolina Press: 75-101.

. 2013. Independencia y educación: Cultura cívica, educación indígena y literatura infantil. México: Colegio de México. Versión digital en Amazon.com.

Turner Bushnell, Amy. 2004. "None of these wandering nations has ever been reduced to the faith': Missions and mobility on the Spanish-American frontier". En James Muldoon, Ed., The Spiritual conversion of the Americas. Gainsville: University Press of Florida: 144-68.

Villavicencio, Juan Joseph de. 1752. Vida y virtudes de el venerable, y apostólico padre Juan de Ugarte de la Compañia de Jesús, Misionero de las Islas Californias, y uno de sus primeros conquistadores. México: Imprenta Real, y más Antiguo Colegio de San Ildefonso. 
